J. Lake Sci. (湖泊科学), 2013, 25(6): 818-826

http: //www.jlakes.org. E-mail : jlakes@niglas.ac.cn

(c) 2013 by Journal of Lake Sciences

\title{
天目湖沙河水库溶解氧分层的季节变化及其对水环境影响的模拟
}

\author{
成晓奕 ${ }^{1,2}$, 李慧望 ${ }^{1 * *}$, 戴淑君 ${ }^{1,2}$ \\ ( 1 : 中国科学院南京地理与湖泊研究所湖泊与环境国家重点实验室, 南京 210008) \\ (2: 中国科学院大学,北京 100049)
}

\begin{abstract}
摘 要: 溶解氧 (DO) 是水体能否维持生态平衡的重要指标, 是湖泊初级生产力与水动力条件的综合反映. 研究 DO 及其 分层的季节变化对认识湖库的富营养化过程有重要意义. 本研究以天目湖沙河水库为例, 运用西澳大学开发的三维水动 力一水质模型—ELCOM-CAEDYM 对天目湖的水温、DO 和总磷 (TP) 进行了为期 1 年的数值模拟. 结果表明, 模型较好 地模拟出了水体温度和 DO 分层过程以及 TP 的时空分布, 3 个指标在水体表层、中层和底层的模拟值与实测值拟合良 好, 均方根误差分别在 $1.8^{\circ} \mathrm{C} 、 1.8 \mathrm{mg} / \mathrm{L}$ 和 $0.003 \mathrm{mg} / \mathrm{L}$ 以内, Nash-Sutcliffe 有效性系数均在 0.7 以上, 相对误差均低于 $10 \%$. 沙河水库不同季节的 DO 垂向分层与温跃层协同变化: 冬季垂向混合; 春季 (4 月)温跃层开始发育, 底部出现氧不 足; 夏季 (7 月) 温跃层位于 4 10 m 之间, 同时底部低氧区 ( DO $<2 \mathrm{mg} / \mathrm{L}$ ) 面积达 $35 \%$; 秋季 ( 9 月末) 低氧区随着温跃层 的消失而消失; 冬季再次垂向混合. 全湖 DO 和 TP 的时空分布表明, 南半库区磷的来源主要是外源输人, 而北半库区磷的 来源主要是由水体底部低氧导致的磷内源释放. DO 季节分层还有可能通过影响藻类活动而对水环境造成影响.
\end{abstract}

关键词: 溶解氧; 热力分层; 天目湖;数值模拟; 总磷;沙河水库

\section{Modeling of seasonal vertical variation of dissolved oxygen and its impacts on water envi- ronment in Shahe Reservoir within Tianmuhu Reservoir}

\author{
CHENG Xiaoyi $^{1,2}$, LI Huiyun ${ }^{1} \&$ DAI Shujun ${ }^{1,2}$ \\ (1: State Key Laboratory of Lake Science and Environment, Nanjing Institute of Geography and Limnology, Chinese Academy \\ of Sciences, Nanjing 210008, P. R. China) \\ (2: University of Chinese Academy of Sciences, Beijing 100049, P. R. China)
}

Abstract:Dissolved oxygen ( DO) is an important indicator of aquatic ecosystem health. The primary production of a lake can be
reflected through DO. Study of DO and its vertical distribution is important to understand the eutrophication process of lakes and
reservoirs. A three-dimensional hydrodynamic-water quality model (ELCOM-CAEDYM) developed by Center for Water Research
of University of Western Australia was applied in order to provide substantial information about vertical distribution of DO at Tian-
muhu Reservoir. The simulation duration is from January $1 \mathrm{st}$ to December $31 \mathrm{st}, 2011(365 \mathrm{~d}$ ). The simulation results of DO, wa-
ter temperature and total phosphorus ( TP) showed good agreement ( $R M S E<1.8^{\circ} \mathrm{C}, 1.8 \mathrm{mg} / \mathrm{L}$ and $0.003 \mathrm{mg} / \mathrm{L} \mathrm{respectively,}$
$N S E>0.7, R E>10 \%$ ) with observed data, which indicated that seasonal variation of vertical distribution of dissolved oxygen
changed together with thermocline. In winter water column fully mixed at Tianmuhu Reservoir. Thermal stratification started in
April and the bottom area became lack of oxygen. Thermocline depth was during $4-10$ m below surface with hypoxia
(DO $<2 \mathrm{mg} / \mathrm{L}$ ) in the bottom water with an area of $35 \%$ of whole bottom area in June. When thermocline disappeared in autumn
the vertically-averaged DO concentration started to increase and the water column tended to mix again. DO and TP concentration
were influenced by inflows in the riverine zone while lacustrine zone was dominated by significant release resulting from hypoxic
events. The vertical distribution pattern of DO induced by thermal stratification in the reservoir could further affect the water envi-
ronment through algae activities.

Keywords: Dissolved oxygen; thermal stratification; Tianmuhu Reservoir; numerical modeling; total phosphorus; Shahe Reservoir

* 中国科学院南京地理与湖泊研究所引进人才启动项目 (NIGLAS2012QD01)、中国科学院 “百人计划” 择优支持项目 (YOBROB045)、国家自然科学基金项目 $(51279194,40871095)$ 和溧阳市沙河水库管理处项目联合资助. $2013-03-$ 12 收稿;2013-06-17 收修改稿. 成晓奕,女,1989 年生, 硕士研究生; E-mail :cxysjs243@ 126. com.

** 通信作者;E-mail:hyli@ niglas. ac.cn. 
受气候变化的影响, 深度为 $7 \mathrm{~m}$ 以上的天然水体在水深方向因物理性质不同而出现有规律的水体分层 现象, 除表水层和底部均温层外,水体中间会出现一个特殊的层结,即为温跃层 (thermocline $)^{[14]}$. 水温决定 了水体密度分层,而与水温变化紧密相关的溶解氧浓度变化是表征水体化学分层的重要指标之一. 溶解氧 (DO) 是健康水生系统所必需的,是水体能否维持生态平衡的重要指标,也是能够提供水质状况信息的状态 变量. 低 DO 水平是水体可能受到污染的信号. DO 在水体中的分层现象对水质和水生生物群落 ${ }^{[5-6]}$ 都有不可 忽视的影响.

目前, 水体分层现象及其后续环境效应已经在诸多水域引起了广泛关注, 如白洋淀水体分层与水质变 化 ${ }^{[7]}$ 、福建山仔水库季节性分层 ${ }^{[8]}$ 以及三峡水库分层对支流影响 ${ }^{[9-10]}$ 等研究中均有相关内容. 然而, 以往研 究大都采用观测法, 存在数据有限、有效数据不连续等不足. 为更充分地了解水体分层的规律, 在有限的人 工采样点获得非连续数据的基础上,引人了数值模拟的方法. 目前横向平均的二维模型发展较为成熟, 而沿 垂向平均的二维也用于弥补一维模型预测中的不足 ${ }^{[11]}$. 实际上,湖库的扩散、紊动和弥散均为复杂的三维运 动,因此研究湖库的水体变化规律适合采用三维数学模型进行模拟. 由西澳大学水研究中心开发的三维水 动力一水质模型, 耦合了湖库三维水动力数值模型 ELCOM 和生态水质数值模型 CAEDYM 两个模块, 前者可 以模拟水体在风应力、热力等条件下水动力的变化状态, 后者可以模拟水体的生物过程和化学过程 ${ }^{[3,12-14]}$. 该数值模型在我国的淀山湖营养物投人响应关系 ${ }^{[15]}$ 、“引江济巢” 工程的水动力与水质 ${ }^{[16]}$ 、珠海水库水温模 拟与水库管理 ${ }^{[17]}$ 和澳大利亚西部的 Swan River 河口藻华暴发和消亡 ${ }^{[18]}$ 等研究中, 作为数值模拟工具被广 泛使用,并获得了显著模拟效果.

天目湖是苏南地区的大 ( II ) 型水库之 一, 承担着饮用水供应、休闲旅游、渔业养殖、 农田灌溉、防洪调蓄等诸多功能. 天目湖的夏 季藻类异常增殖问题却已经困扰水库管理十 几年. 本文以天目湖沙河水库为例, 尝试采用 ELCOM-CAEDYM 模型来模拟溶解氧分层的 季节变化,讨论对水环境造成的影响, 以期更 好地认识水体分层的规律, 从而为天目湖水环 境的管理和改善提供可靠的科学依据.

\section{1 研究区域与研究方法}

\section{1 研究区域概况}

天目湖 $\left(31^{\circ} 18^{\prime} \mathrm{N}, 119^{\circ} 25^{\prime} \mathrm{E}\right)$ 位于江苏省 常州溧阳市南部丘陵地区,包括沙河和大溪两 个水库, 其中沙河水库 (图 1) 作为溧阳市主要 饮用水水源地 ${ }^{[19]}$, 承担着溧阳市 60 万人口的 供水安全. 本文以沙河水库为研究对象, 对水 温和 DO 季节性分层情况及其对水环境的影 响进行分析. 沙河水库水域面积为 $12 \mathrm{~km}^{2}$, 最 大蓄水量约为 $1.3 \times 10^{8} \mathrm{~m}^{3[20-21]}$, 湖底高程由 南向北递减, 北部大坝处地面高程 $22 \mathrm{~m}^{[22]}$. 全 湖平均水深 $7.5 \mathrm{~m}$, 最大水深为 $14 \mathrm{~m}^{[23]}$, 由于 水体流动性差, 易形成分层. 沙河水库主要人 流分别为南部的平桥河、下宋河和中田河, 人 库总流量约为 $1.9 \mathrm{~m}^{3} / \mathrm{s}$, 水库出流量在 $0.5 \sim$ $10 \mathrm{~m}^{3} / \mathrm{s}$ 范围内根据需要进行人工调节.

\section{2 研究方法}

建立沙河水库三维 ELCOM-CAEDYM 模

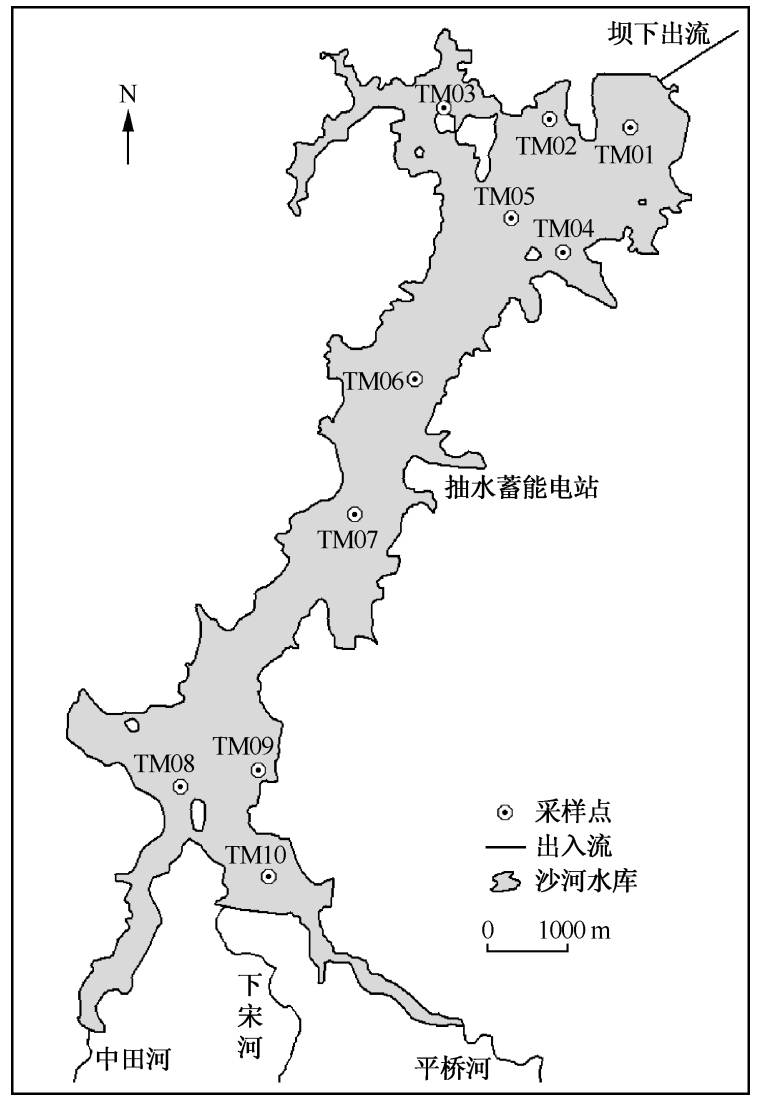

图 1 沙河水库采样点及出入流分布

Fig. 1 Distribution of sampling sites, inflows and withdraw at Shahe Reservoir 
型,需要准备如下文件:

1) 水下地形文件,该文件以 $96 \times 67$ 的二维矩阵来描述沙河水库的水下地形,水域内各元素代表水深, 陆面则采用 9999 代替.

2 ) 边界条件, 即气象文件和出人流文件. 其中, 气象文件包括逐日大气压、气温、相对湿度、降水、风速、 风向和太阳辐射数据; 出人流文件包括逐日人流、出流流量, 以及人流河道的水温、DO、盐度、氨氮、硝态氮、 正磷酸盐、溶解性有机氮 (DONL)、颗粒态有机氮 (PONL)、溶解性有机磷 (DOPL)、颗粒态有机磷 ( POPL) 和 悬浮颗粒物浓度 $(\mathrm{SS})$ 等水质指标.

3 ) 初始条件,即模拟开始时的水质情况.

4 ) 参数文件,模型参数值的确定是在参考相关文献的基础上,结合沙河水库 2010 年 10-12 月的水温、 DO 和 TP 的实测数据, 以手动率定的方式进行修正. ELCOM-CAEDYM 模型构建过程中与 DO 和 TP 相关的 生物化学过程如表 1 所示, 主要参数取值见表 2 .

表 1 CAEDYM 模型主要计算公式*

Tab. 1 Summary of equations used in CAEDYM

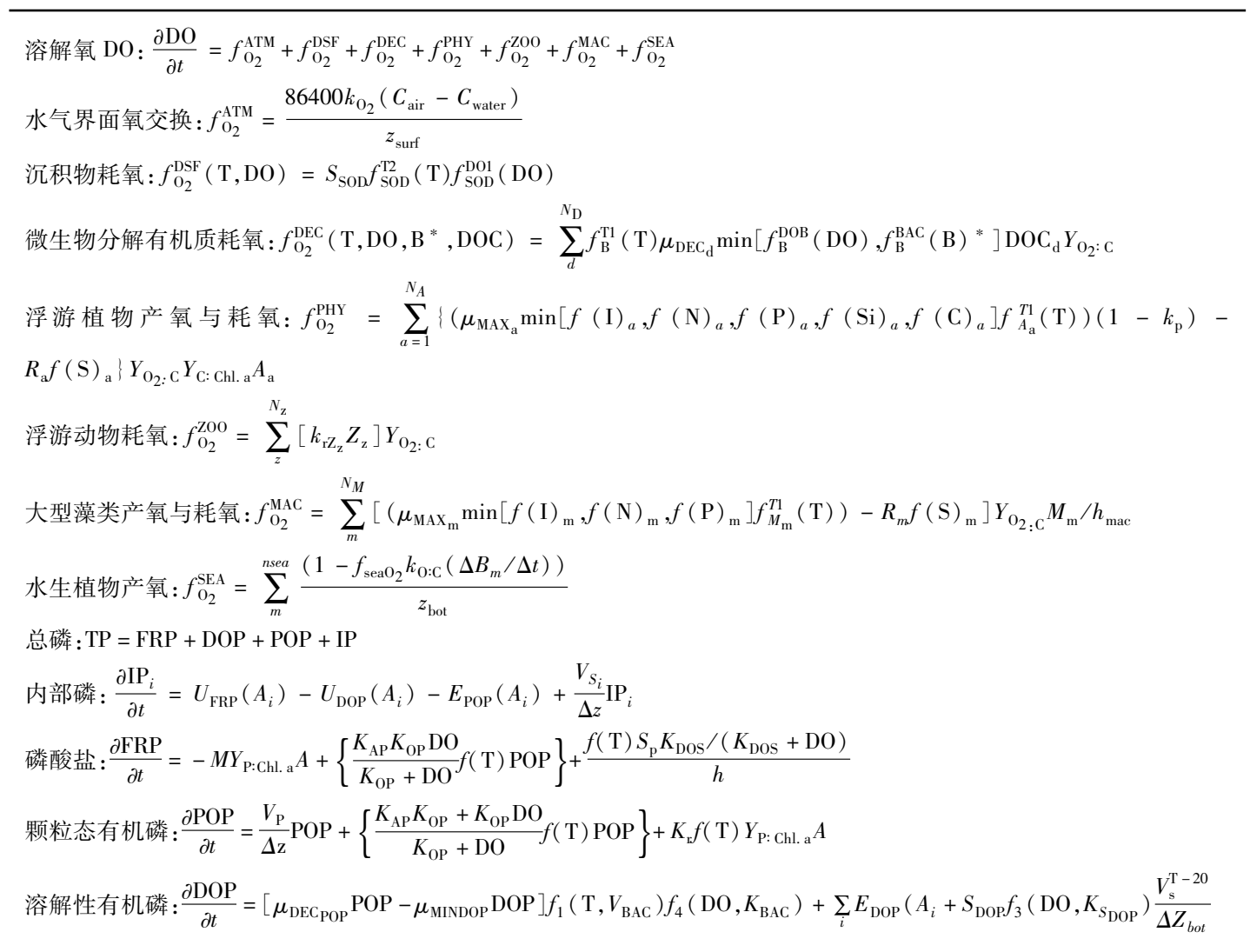

$* k_{\mathrm{O}_{2}}$ 为氧交换系数, $C_{\text {air }}$ 为空气中氧浓度, $C_{\mathrm{water}}$ 为水中氧浓度, $z_{\text {surf }}$ 为表层深度; $S_{\mathrm{SOD}}$ 为泥水界面氧通量, $K_{\mathrm{DO}}$ SOD 为沉积物 需氧量的半饱和常数; $Y_{\mathrm{O}_{2}: \mathrm{C}}$ 为氧碳比, $\mu_{\mathrm{DEC}_{\mathrm{d}}}$ 为 $\mathrm{DOC}$ 的最大矿化速率, $B$ 为细菌的数量; $a$ 为浮游植物种类, $\mu_{\mathrm{MAX}_{\mathrm{a}}}$ 为浮游植 物最大生长速率, $A_{\mathrm{a}}$ 为浮游植物的量 $\left(\mathrm{g} \mathrm{Chl} . \mathrm{a} / \mathrm{m}^{3}\right), k_{\mathrm{p}}$ 为光呼吸所用速率, $R_{\mathrm{a}}$ 为呼吸 $/$ 代谢损失速率 $\left(\mathrm{d}^{-1}\right), Y_{\mathrm{C}: \mathrm{Chl}} \mathrm{a}$ 为碳 和叶绿素比; $z$ 为浮游动物种类, $k_{\mathrm{r}} \mathrm{z}_{\mathrm{z}}$ 为浮游动物呼吸速率, $Z_{\mathrm{z}}$ 为浮游动物的量 $\left(\mathrm{g} \mathrm{C} / \mathrm{m}^{3}\right) ; m$ 为大型藻类种类, $\mu_{\mathrm{MAX}_{\mathrm{m}}}$ 为大 型藻类最大生长速率, $M_{\mathrm{m}}$ 为大型藻类生物量 $\left(\mathrm{g} \mathrm{C} / \mathrm{m}^{2}\right), h_{\mathrm{mac}}$ 为沉积物中藻类所处深度, $R_{\mathrm{m}}$ 为呼吸/代谢损失速率 $\left(\mathrm{d}^{-1}\right)$; $\Delta B_{\mathrm{m}} / \Delta \mathrm{t}$ 为水生植物生物量随时间的变化率 $\left(\mathrm{g} \mathrm{C} /\left(\mathrm{m}^{2} \cdot \mathrm{d}\right)\right), z_{\mathrm{bot}}$ 为最底层深度, $k_{\mathrm{O}: \mathrm{C}}$ 为水生植物生物量改变对应的氧消耗 量 $\left(\mathrm{g} \mathrm{O}_{2} / \mathrm{g} \mathrm{C}\right), f_{\mathrm{sea}_{2}}$ 为沉积物产氧与水体产氧的比. IP 为藻类内部的磷, $K_{\mathrm{P}_{\mathrm{a}}}$ 为 P 的半饱和常数, $K_{\mathrm{OP}}$ 为需氧条件下 $\mathrm{POP}$ ( 颗粒态有机磷) 的矿化速率, $K_{\mathrm{AP}}$ 为厌氧条件下 $\mathrm{POP}$ 的矿化速率, $\mu_{\mathrm{DEC}}$ POP 为在 $20^{\circ} \mathrm{C}$ 微生物分解 $\mathrm{POP}$ 的最大速率, $\mathrm{DOP}$ 为 可溶性有机磷, $K_{\mathrm{r}}$ 为呼吸作用速率, $\Delta z$ 为网格厚度, $\Delta z_{\mathrm{bot}}$ 为沉积物网格厚度. 
5 ) 模拟文件,该数值模型使用笛卡尔正交网格,垂直方向共分为 40 层,各层厚度为 $0.5 \mathrm{~m}$; 模拟时间步 长为 $600 \mathrm{~s}$, 模拟时段为 2011 年 1 月 1 日- 12 月 31 日,共 365 天.

为验证 ELCOM-CAEDYM 模型在沙河水库的模拟效果, 本文采用均方根误差 $(R M S E)^{[24]}$ 、Nash-Sutcliffe 相关系数 $(N S E)$ 和相对误差 $(R E)^{[25-26]}$ 作为评价指标:

$$
\begin{gathered}
\text { RMSE }=\sqrt{\frac{1}{N} \sum_{i=1}^{N}\left(S_{i}-O_{i}\right)^{2}} \\
N S E=1-\sum_{i=1}^{N}\left(S_{i}-O_{i}\right)^{2} / \sum_{i=1}^{N}\left(O_{i}-\bar{O}\right)^{2} \\
R E=\frac{1}{N} \sum_{i=1}^{N}\left|S_{i}-O_{i}\right| / \bar{O}
\end{gathered}
$$

式中, $O_{i}$ 为相应水质指标 (水温、 $\mathrm{DO}$ 和 $\mathrm{TP}$ ) 的实测值, $\bar{O}$ 为实测数据的算数平均值, $S_{i}$ 为模拟值.

$R M S E$ 表示样本的离散程度,有量纲,值越 小说明模拟效果越好. NSE 反映了模拟值与实 测值的拟合程度, $N S E \leqslant 1$, 无量纲. 其中, $N S E=$ 1 说明完全拟合, $N S E \leqslant 0$ 说明拟合程度极差, $N S E$ 值越接近 1 , 说明拟合程度越好, 模型模拟 效果越好,一般认为 $N S E>0.7$ 时模拟结果较 为可靠. $R E<30 \%$ 时, 认为模型结果较为准确.

\section{3 资料选取}

采样点 TM01 处投放温度溶氧链, 每隔 $1 \mathrm{~m}$ 安放一个温度溶氧探头. TM09 点因常年水位太 低而无法到达. 其余 8 个采样点测定表层 (水下 约 $50 \mathrm{~cm}$ )、中层 (约 $1 / 2$ 水深) 和底层 (湖底以 上 $1 \sim 2 \mathrm{~m}$ 处) 的温度和 DO. TM01 TM08 和 TM10 各点均测定表层的 TP.

表 2 ELCOM-CAEDYM 模型主要参数及其取值

Tab. 2 Parameters of ELCOM-CAEDYM model

\begin{tabular}{cc}
\hline 参数 & 取值 \\
\hline 总体消光系数 & 4.9 \\
水体平均反射率 & 0.08 \\
表面热传递系数 & 0.0013 \\
风力拖拽系数 & 0.0013 \\
底部单元拖拽系数 & 0.005 \\
呼吸作用碳氧比 & 2.67 \\
藻类最大生长速率 & $0.34 \mathrm{~d}^{-1}$ \\
磷的半饱和常数 & $0.015 \mathrm{mg} / \mathrm{L}$ \\
温度限制函数的常数因子 & 1.06 \\
再具浮速率常数 & $0.025 \mathrm{mg} \mathrm{Chl.} \mathrm{a/}\left(\mathrm{m}^{2} \cdot \mathrm{d}\right)$ \\
\hline
\end{tabular}

逐日气象数据,包括大气压、气温、相对湿度、降水、风速、风向和太阳辐射, 由溧阳市气象局提供. 逐日 人库流量和出库流量数据从溧阳市沙河水库管理处获取. 10 个采样点和 3 条人流的水质数据由每个月的人 工巡测获得.

\section{2 结果与分析}

\section{1 模型验证}

模型采用 2011 年逐月 DO、温度和 TP 实测值进行验证, 由于篇幅限制本文仅展示水深最大处 TM03 点 位表层、中层和底层 DO 和温度的验证结果 (图 2). 对于 TP, 由北向南选择 3 个有代表性的点位 TM03、TM06 和 TM10 展示表层的验证结果(图 3 ).

沙河水库表层、中层和底层水体 DO 的 $R M S E$ 在 $1.0 \sim 1.8 \mathrm{mg} / \mathrm{L}$ 范围内, $N S E$ 均大于 $0.7, R E$ 在 $7 \% \sim$ $10 \%$ 范围内; 水温的 $R M S E$ 均小于 $1.8^{\circ} \mathrm{C}, N S E$ 均大于 $0.9, R E$ 均小于 $4 \%$; TP 的 $R M S E$ 均小于 $0.003 \mathrm{mg} / \mathrm{L}$, $N S E$ 高于 $0.9, R E$ 控制在 7\% 以内 (表 3 ) ; 以上结果均符合模型准确度的一般要求. 由此表明 ELCOM-CAEDYM 在沙河水库的模拟中, 能够对 DO 、水温和 TP 进行较精确的模拟. 因此在实测值有限的情况下, 可用模 拟值代替实测值来进行研究和分析,结果可信度良好.

\section{2 沙河水库水温与溶解氧季节分层模拟}

一般而言, 水库平均水深达 $7 \mathrm{~m}$ 以上会出现水体分层现象 ${ }^{[27]}$. 廓线是描述气象要素和污染物浓度垂直 分布的曲线或函数. 通过沙河水库 2011 年 2-9 月共 8 个月的水温和 DO 廓线,可以看出沙河水库垂向温度 廓线随着季节变化而变化 (图 4 ). 在 12 月至次年 2 月, 受冬季低温、大风和弱太阳辐射的影响,水体从表层 到底层垂向充分混合. 从 4 月末开始,随着太阳辐射的增强, 气温不断升高, 表层水温从冬季的 $10^{\circ} \mathrm{C}$ 以下升 
至 $17^{\circ} \mathrm{C}$, 湖水开始出现明显的温度分层, 从 6 月开始, 温跃层逐渐由水体下部向中部延伸, 并在 7 月达到顶 峰, 表层和底层水温可相差 $6^{\circ} \mathrm{C}$. 温跃层存在于 $4 \sim 10 \mathrm{~m}$ 水深范围内, 其温度下降梯度大于 $1^{\circ} \mathrm{C} / \mathrm{m} .9$ 月以后, 层结逐渐消失, 至 9 月末表层和底层水温相差小于 $1^{\circ} \mathrm{C}$, 表层水温从 7 月末的近 $30^{\circ} \mathrm{C}$ 逐渐下降至 $24^{\circ} \mathrm{C}$. 经过 一个冬天后, 水库上下层水温再次达到一致. 沙河水库水体 DO 的垂直廓线亦随季节变化而变化, 其趋势与 温度一致, 而变化幅度较温度大 (图 4), 由此能够更加直观地反映沙河水库水体分层的变化规律. $1-3$ 月份 全断面 DO 均在 $10 \mathrm{mg} / \mathrm{L}$ 以上, 接近饱和, 且垂直方向完全混合. 从春季 4 月开始, $6 \mathrm{~m}$ 以下的水体 DO 开始 显著下降至 $10 \mathrm{mg} / \mathrm{L}$ 以下. 从 4 月出现温跃层到 6 月继续层化, 水体底部 DO 不断降低并在 $7.5 \mathrm{~m}$ 以下出现 $\mathrm{DO}$ 小于 $5 \mathrm{mg} / \mathrm{L}$ 的氧不足现象, 到 $7 、 8$ 月份层结最为明显, 沙河水库 7 月份在 $8 \mathrm{~m}$ 以下甚至出现 DO 小于 $2 \mathrm{mg} / \mathrm{L}$ 的低氧区, 这种低氧区到了 8 月份扩展到 $5.5 \mathrm{~m}$ 至湖底的整个区域. 直到 9 月, 表层 DO 开始渐渐恢 复, 随着温跃层的消失, 水中的氧得以向水体下部延伸. 进人 10 月后, 底部 DO 也恢复到好氧状态 (图 4).

表 3 沙河水库 ELCOM-CAEDYM 模型模拟结果评价指标 ${ }^{*}$

Tab. 3 Statistical variables for ELCOM-CAEDYM evaluation in Shahe Reservoir

\begin{tabular}{|c|c|c|c|c|c|c|c|c|c|}
\hline \multirow{2}{*}{ 评价指标 } & \multicolumn{3}{|c|}{ DO } & \multicolumn{3}{|c|}{ 温度 } & \multicolumn{3}{|c|}{ TP } \\
\hline & 表层 & 中层 & 底层 & 表层 & 中层 & 底层 & TM03 & TM06 & TM10 \\
\hline RMSE & 0.96 & 0.99 & 1.75 & 1.58 & 1.78 & 1.24 & 0.0026 & 0.0022 & 0.0024 \\
\hline$N S E$ & 0.76 & 0.83 & 0.79 & 0.99 & 0.98 & 0.99 & 0.93 & 0.94 & 0.97 \\
\hline$R E$ & $7 \%$ & $8 \%$ & $10 \%$ & $4 \%$ & $4 \%$ & $2 \%$ & $7 \%$ & $4 \%$ & $3 \%$ \\
\hline
\end{tabular}

* DO 、温度和 TP 的 $R M S E$ 单位分别为 $\mathrm{mg} / \mathrm{L} 、{ }^{\circ} \mathrm{C}$ 和 $\mathrm{mg} / \mathrm{L}$.
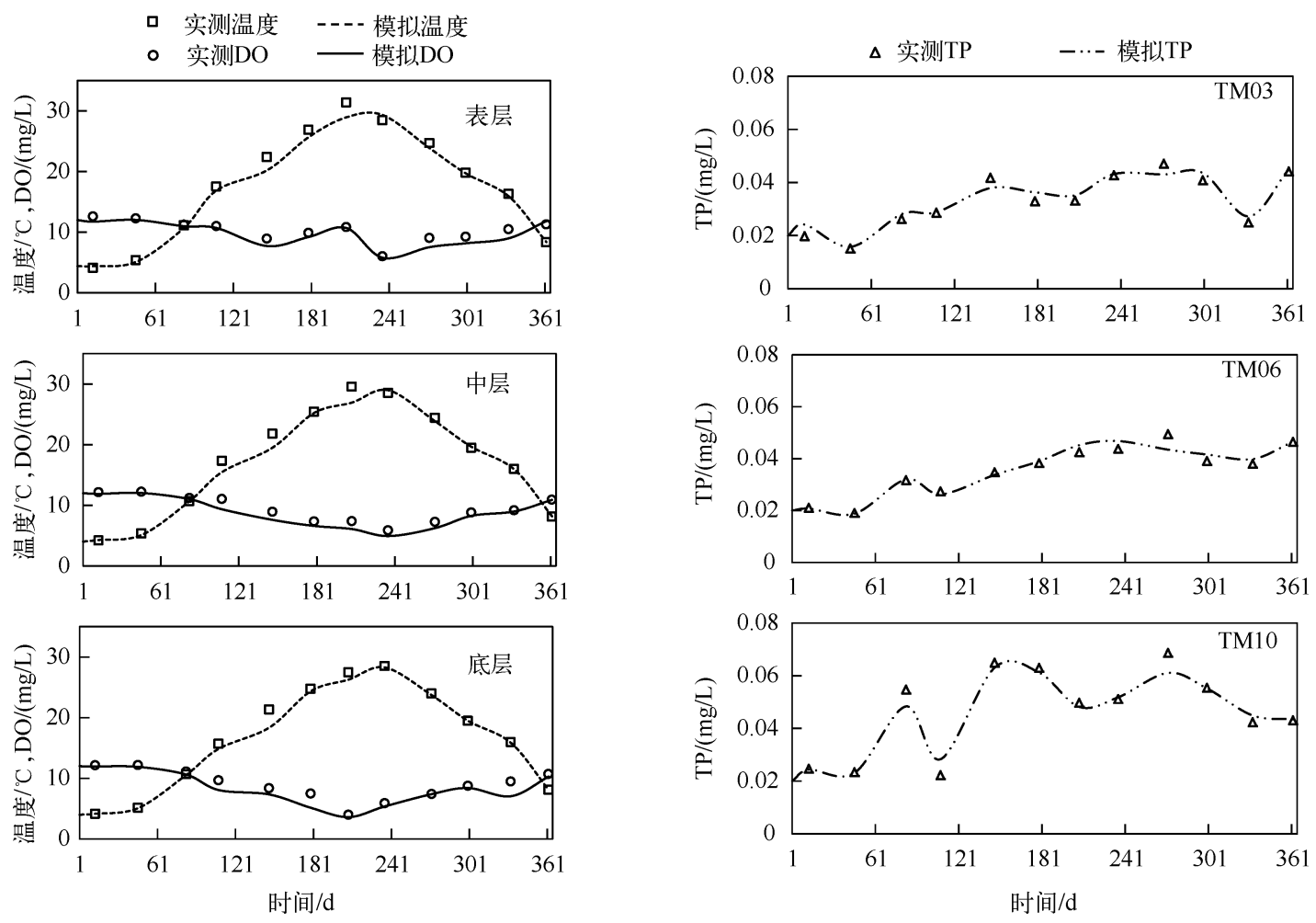

图 22011 年沙河水库 TM03 表层、中层和底

层的 DO 和水温模拟值与实测值的对比

Fig. 2 Comparison of observations and simulations of DO and water temperature at TM03 ( surface, middle and bottom ) of Shahe Reservoir in 2011

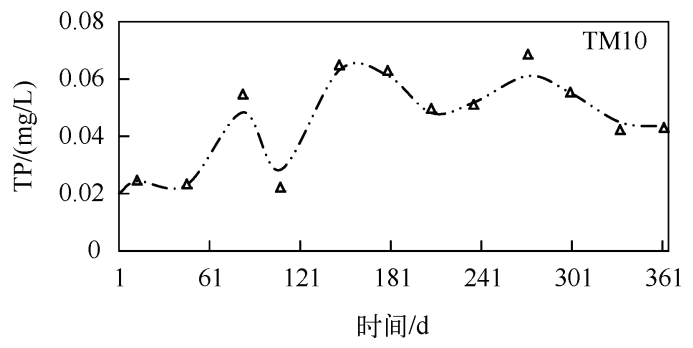

图 32011 年沙河水库 TM03、TM06 和 TM10 的 $\mathrm{TP}$ 模拟值与实测值的对比

Fig. 3 Comparison of observations and simulations of TP at TM03, TM06 and TM10 of Shahe Reservoir in 2011 
由于仪器原因,TM01 站点 5 月份的实测值仅为表层到水下 $7 \mathrm{~m}$ 处,而当时的水深已接近 $10 \mathrm{~m}$. 可见, 在实 测数据不足的情况下, 模型模拟得到深水处 7 10 $\mathrm{m}$ 的水温和 DO, 为进一步研究进行了必要的数据补充.

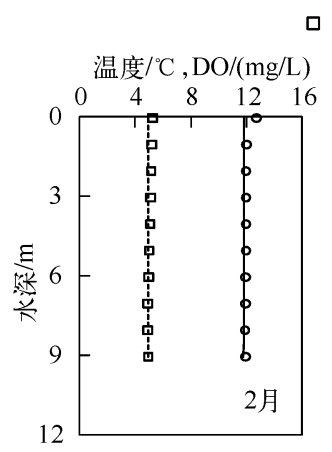

$$
\text { 口 实测温度 }
$$

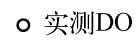

温度 $/{ }^{\circ} \mathrm{C}, \mathrm{DO} /(\mathrm{mg} / \mathrm{L})$
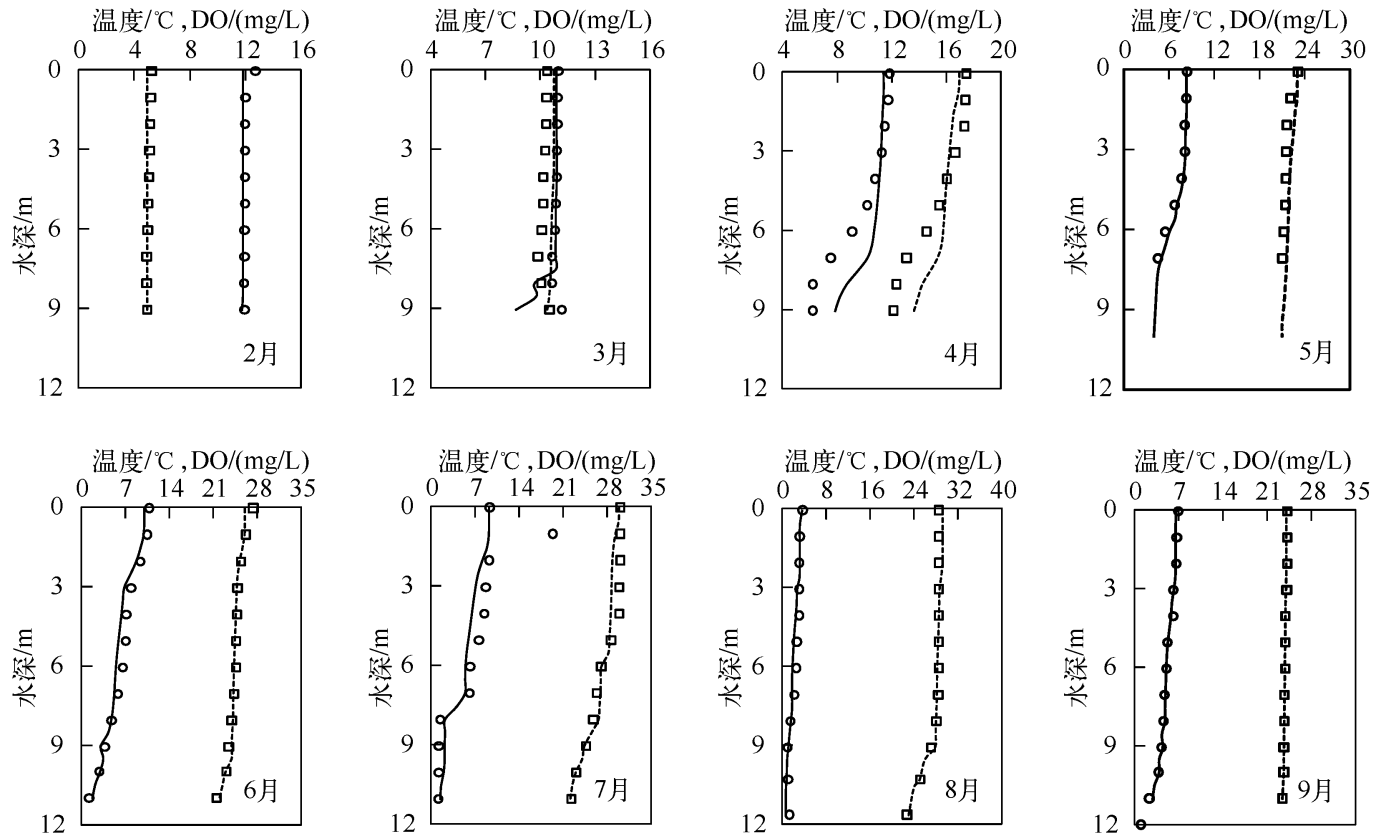

图 42011 年沙河水库水温、DO 季节性分层模拟结果

Fig. 4 Simulations of seasonal vertical variation of water temperature and DO at Shahe Reservoir in 2011

\section{3 沙河水库溶解氧水平分布模拟}

图 5 为每月采样当天 DO 的空间分布模拟结果,每个网格的 DO 为其垂向平均值,该图更加全面地反映 了全库的水环境状况. 沙河水库以其狭长的特征而被分为南半库区和北半库区两部分. 南部承接平桥河、下 宋河和中田河 3 条人流来水,该区域水体有一定的流速而使得水流能自然地向下游流动, 呈河流相. 北半库 区,由于大坝拦截,人工控制出水量,流速相对缓慢,垂向会出现分层,呈湖泊相.

在南半库区, DO 值在 $1 、 5 、 7$ 和 11 月明显低于其他区域,主要受上游来水的影响, 与水温关系不明显, 更多取决于接纳来水中耗氧物质的总量. 当外源耗氧物质聚集增多时, DO 随之被消耗,逐渐降低. 北半库区 的 DO 主要受到水体热力分层的影响,首先 DO 随温度上升而明显下降,加之温跃层阻碍水体表层的氧在垂 向混合,使得坝前部分垂向平均的 DO 从 4 月的 $10 \mathrm{mg} / \mathrm{L}$ 下降到 8 月仅为 $2.3 \mathrm{mg} / \mathrm{L}$.

然而 DO 在夏季随水温升高而下降的值并不是全库均匀的. 由图 5 可见,库区中部 TM06 附近的 DO 较 周围水体略高, 这是因为抽水蓄能电站在春、夏季对 DO 的下降有一定缓冲作用. 一般情况下,春、夏季节为 用电高峰期, 抽水蓄能电站由于调峰需求而泄水发电. 电站对水温的年内变化有 “坦化” ${ }^{[29]}$ 的效应, 即 5-9 月份, 电站出水水温低于库区水温, 从而减缓了 DO 下降的速度,而 10 月至次年 4 月, 电站出水水温高于库 区水温,亦减缓了 DO 上升的速度,使得 DO 的变化趋于缓和.

\section{3 讨论}

\section{1 水体热力分层对 DO 的影响}

沙河水库 DO 的季节性分层受水体热力分层的影响较大. 冬季气温低、水温低、氧气在水体中溶解度很 大, 且冬季有机物耗氧速率较低, 加之沙河水库地区冬季表面无冰, 不存在冰盖阻挡阳光和复氧现象, 使得 冬季沙河水库处于好氧状态 


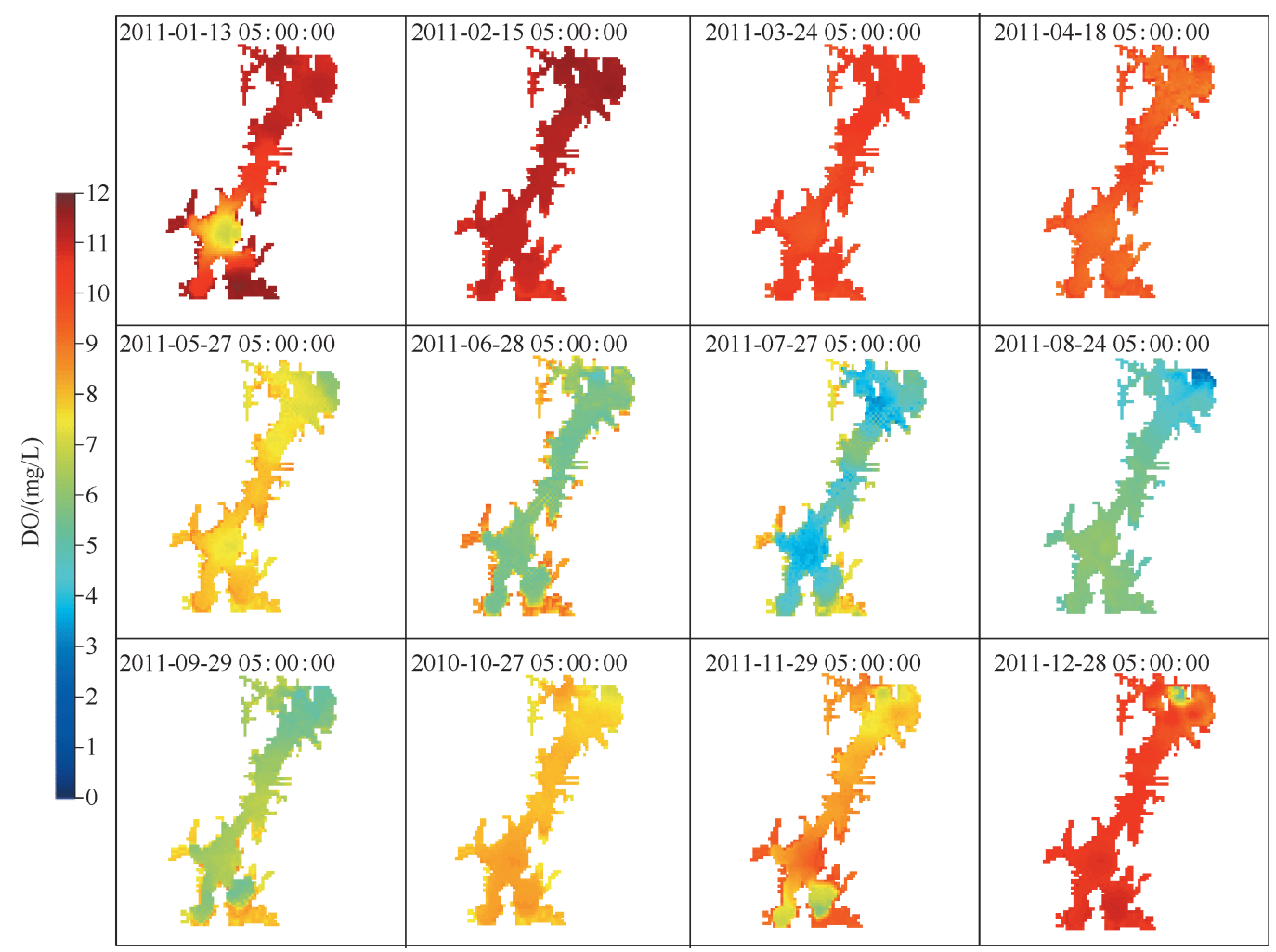

图 52011 年沙河水库垂向平均 DO 的空间分布模拟结果

Fig. 5 Simulations of special distribution of vertically-averaged DO at Shahe Reservoir in 2011

进人春季后, 温跃层开始发育, 水体中开始出现氧不足的区域, 而到了夏季则温跃层完全形成, 此时 DO 最大浓度梯度出现的深度与温跃层一致,低氧区从 6 月份开始形成 (图 6). 由于光合作用和大气的扩散,整 个夏季表层水的 DO 值都很高, $6 、 7$ 月份表层 DO 均在 $9 \mathrm{mg} / \mathrm{L}$ 以上. 温跃层阻挡复氧达到底部, 且底部光线 不足, 光合作用微弱. 均温层被有效地切除了一切氧气来源, 但是库区底部的有机体继续呼吸并消耗底部本 已不足的氧气, 进而造成了 7.8 月份在沙河水库底部出现低氧区, 此时的低氧区面积分别占水库总面积的 $35.16 \%$ 和 $19.62 \%$. 秋季温跃层逐渐弱化, 水体垂向趋于混合, 9 月份以后低氧区逐渐消失, 直至冬天 DO 垂 向不再分层.

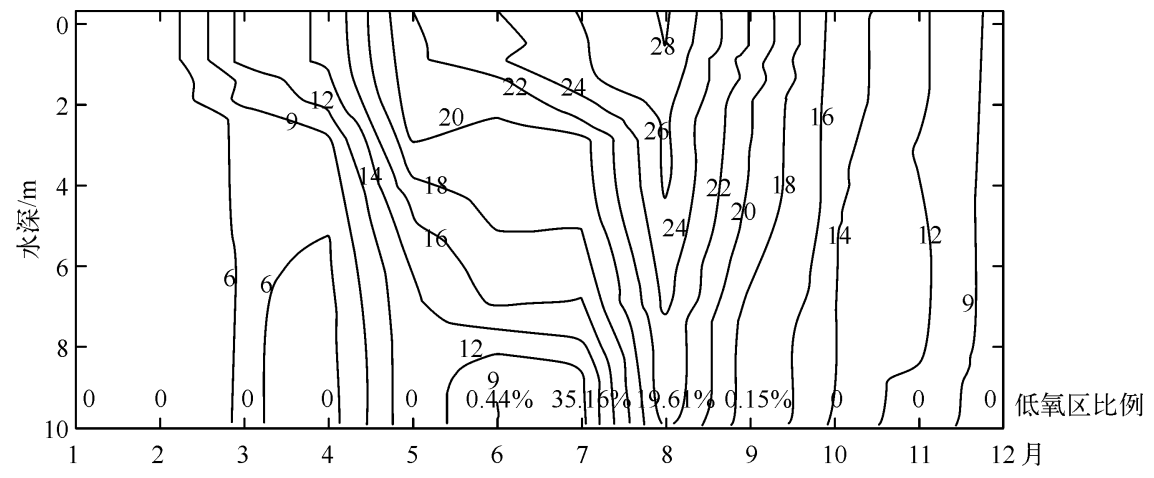

图 62011 年沙河水库等温线 $\left({ }^{\circ} \mathrm{C}\right)$ 与低氧区比例图

Fig. 6 Isotherm and the proportion of hypoxia area at Shahe Reservoir in 2011 


\subsection{DO 季节性分层对环境的影响}

DO 季节分层造成的底部低氧环境可能促进了沙河 水库沉积物中磷的释放. 磷是藻类生长所必须的营养物 质,并且是将阳光转化为可利用能量的关键成分. 在许 多淡水系统中, 磷是限制性营养物质. 图 7 为沙河水库 TM01 点位 2011 年 1-12 月 TP 随水深的变化情况. 图 中每一根柱内部从左到右依次表示从表层到底层的 TP. 在 3-8 月份沙河水库的 TP 呈现出明显的底部高于 表层的现象,其中最为明显的是 3 月和 5 月, 底层 TP 比 表层 TP 分别高 0.019 和 $0.013 \mathrm{mg} / \mathrm{L}$, 增幅达到 $141 \%$ 和 $85 \%$. 而春、夏季沙河水库的底部 DO 也处在较低水平, 尤其 5 月份开始出现缺氧区. 这样一组时间吻合的关系, 可以说明此时沙河水库坝前区域是因为低氧条件而造成 内源释放. 这与相关文献中得到的结论一致 ${ }^{[29-31]}$.

DO 季节分层还有可能通过影响藻类活动而对水环 境造成影响. 沙河水库夏季表层水温保持在 $25^{\circ} \mathrm{C}$ 以上, 且光照充足,藻类便能够快速生长, 并通过光合作用产 氧,使得夏季表层 DO 升高甚至过饱和. 如果此时风速 较小,则藻类大量堆积死亡. 这些藻类颗粒沉降到近底 层,被细菌降解而消耗大量 DO,进而与温跃层存在共同

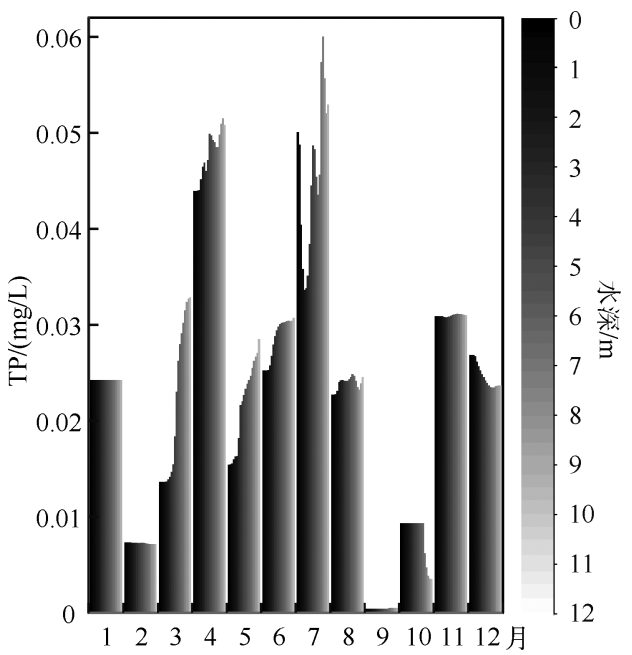

图 72011 年沙河水库 TM01 处各层 TP 模拟

Fig. 7 Simulations of TP in every levels at TM01 site of Shahe Reservoir, 2011 作用, 促进底部缺氧层的发育. 由此造成内源磷的释放, 使得 TP 浓度再次升高, 当水体底部的磷进人真光层 后, 便会引起新一轮的藻类生长, 如此循环.

\section{4 结论}

在天目湖沙河水库发展 ELCOM-CAEDYM 三维模型的主要目的是将数值模型作为湖泊研究、管理和策 略制定的工具. 通过该模型在天目湖沙河水库 365 天的数值模拟,得到以下结论:

1) 三维水动力一水质模型 ELCOM-CAEDYM 能较好地模拟沙河水库水体 DO 、水温和 TP 的时空分布情 况,完整地展现了 DO 分层的季节性变化,并得出 DO 作为环境因子对水体总磷浓度的影响. 数值模拟可以 作为一个行之有效的工具, 为科研和管理提供更好的依据.

2) 沙河水库不同季节的 DO 垂向分层与温跃层协同变化: 冬季垂向混合; 春季 4 月份温跃层开始发育, 底部出现氧不足;夏季 7 月份温跃层存在于 $4 \sim 10 \mathrm{~m}$ 范围同时底部低氧区面积达 $35 \%$; 秋季 9 月末低氧区 随着温跃层的消失而消失; 冬季再次垂向混合.

3) 沙河水库南半库区的 TP 主要由外源输人,北半库区的 TP 主要来源于水体底部低氧导致的内源释 放. DO 季节分层还有可能通过影响藻类活动而对水环境造成影响.

4) 数值模型作为研究工具, 可以通过改变出人流和气象等边界条件模拟气候变化等外界条件对沙河水 库水体的影响, 以及预测一定时间内水体可能发生的变化. 这种通过情景模拟预测水体变化的方法, 是今后 研究的目标和方向.

致谢: 感谢朱广伟研究员对本文撰写给予的大力学术指导和数据支持, 感谢朱梦圆博士在论文修改中给予 的帮助,感谢罗潡葱教授和西澳大学水研究中心提供了模型软件, 感谢李恒鹏老师提供的十思园气象数据, 感谢陈伟民教授、溧阳市天目湖镇高㭉平书记等在数据采集、分析中的帮助.

\section{5 参考文献}

[ 1 ] Trolle D, Jorgensen TB, Jeppesen E. Predicting the effects of reduced external nitrogen loading on the nitrogen dynamics and ecological state of deep Lake Ravn, Denmark, using the DYRESM-CAEDYM model. Limnologica, 2008,38(3/4) : 220-232.

[ 2 ] Trolle D, Hamilton DP, Pilditch CA et al. Predicting the effects of climate change on trophic status of three morphologically varying lakes: Implications for lake restoration and management. Environmental Modelling \& Software, 2011,26(4) : 
354-370.

[ 3 ] Marce R, Moreno-Ostos E, Garcia-Barcina JM et al. Tailoring dam structures to water quality predictions in new reservoir projects: Assisting decision-making using numerical modeling. Journal of Environmental Management, 2010,91 (6) : 1255-1267.

[ 4 ] Chung SW, Hipsey MR, Imberger J. Modelling the propagation of turbid density inflows into a stratified lake: Daecheong Reservoir, Korea. Environmental Modelling \& Software, 2009, 24(12):1467-1482.

[5] 陈 芳, 孙 忠, 王跃斌. 三疮梭子蟹不同养殖模式池塘夏季溶解氧变化特征的研究. 浙江海洋学院学报: 自然科 学版, 2011, (3):221-225.

[6] 林国恩,望 甜,林秋奇等. 广东流溪河水库湖沼学变量的时空动态特征. 湖泊科学, 2009,21(3):387-394.

[ 7 ] 卢玉明. 白洋淀水中 DO 的变化规律初探. 环境科学, 1995, (S1 ) :14-16,20.

[8] 苏玉萍, 郑达贤, 林婉珍等. 福建省山仔水库水体季节性分层特征研究. 福建师范大学学报: 自然科学版, 2007, (3) $: 14,25$.

[9] 王 暗,戴会超. 大型水库水温分层影响及防治措施. 三峡大学学报: 自然科学版,2009,(6):11-14,28.

[10］杨正健, 刘德富, 纪道斌等. 三峡水库 $172.5 \mathrm{~m}$ 蓄水过程对香溪河库湾水体富营养化的影响. 中国科学: 技术科学, 2010 , (4) :358-369.

[11] 李冰冻,李克锋,李 嘉等. 水库温度分层流动的三维数值模拟. 四川大学学报:工程科学版, 2007, (1):23-27.

[12] Burger DF, Hamilton DP, Pilditch CA. Modelling the relative importance of internal and external nutrient loads on water column nutrient concentrations and phytoplankton biomass in a shallow polymictic lake. Ecological Modeling, 2008 , 211 $(3 / 4): 411-423$.

[13] Gal G, Hipsey MR, Parparov A et al. Implementation of ecological modeling as an effective management and investigation tool: Lake Kinneret as a case study. Ecological Modeling, 2009,220(13/14): 1697-1718.

[14] Ozkundakci D, Hamilton DP, Trolle D. Modelling the response of a highly eutrophic lake to reductions in external and internal nutrient loading. New Zealand Journal of Marine and Freshwater Research, 2011, 45 (2) : 165-185.

[15] 卢 嘉,陈小华, 李小平. 基于 ELCOM-CAEDYM 模型的淀山湖营养物投人响应关系的模拟. 湖泊科学,2011,23 (3) :366-374.

[16] 谢兴勇,钱 新,钱 瑜等. “引江济巢”工程中水动力及水质数值模拟. 中国环境科学, 2008, (12):1133-1137.

[17] 张 帅. 珠海市两座供水水库水质模拟及在水质管理中的应用 [学位论文].广州: 暨南大学,2011.

[18 ] Hipsey MR, Antenucci J, Brookes JD et al. A three dimensional model for Cryptosporidium dynamics in lakes and reservoirs. International Journal of River Basin Management, 2004,2(3) : 181-197.

［19］高永霞,朱广伟,贺冉等. 天目湖水质演变及富营养化状况研究. 环境科学, 2009,(3):673-679.

[20] 张运林,陈伟民,杨顶田等. 天目湖热力学状况的监测与分析. 水科学进展, 2004,(1):61-67.

[21] 黄群芳, 张运林, 陈伟民等. 天目湖水文特征变化及其对上游湿地和湖泊生态环境的影响. 湿地科学, 2007,(1): 51-57.

[22] 贺冉舟, 罗潋葱, 朱广伟等. 天目湖溶解氧变化特征及对内源氮释放的影响. 生态与农村环境学报, 2010, (4): 344-349.

[23] 张运林, 陈伟民, 杨顶田等. 天目湖 $2001 \sim 2002$ 年环境调查及富营养化评价. 长江流域资源与环境, 2005, (1)： 99-103.

[24] Luo LC, Hamilton DP, Han BP. Estimation of total cloud cover from solar radiation observations at Lake Rotorua, New Zealand. Solar Energy, 2010,84(3) : 501-506.

[25] Krause P, Boyle D, Bäse F. Comparison of different efficiency criteria for hydrological model assessment. Advances in GeoSciences, 2005,5 :89-97.

[26] Van Der Perk M, Bierkens MF. The identifiability of parameters in a water quality model of the Biebrza River, Poland. Journal of Hydrology, 1997,200 ( 1 ) : 307-322.

[27] 叶守泽. 水库水环境模拟预测与评价. 北京: 中国水利水电出版社, 1998:124.

[28] 蒋 红, 卢红伟, 游 湘等. 雅砻江锦屏一级水电站水温特性及分层取水方案研究. 水电 2006 国际研讨会论文 集, 2006 .

[29] 贺冉冉, 高永霞, 王 芳等. 天目湖水体与沉积物中营养盐时空分布及成因. 农业环境科学学报, 2009, (2): 353-360.

[30 ] Trolle D, Skovgaard H, Jeppesen E. The Water Framework Directive: Setting the phosphorus loading target for a deep lake in Denmark using the 1D lake ecosystem model DYRESM-CAEDYM. Ecological Modeling, 2008 ,219(1/2) : 138-152.

[31］朱广伟,秦伯强,张 路等. 太湖底泥悬浮中营养盐释放的波浪水槽试验. 湖泊科学, 2005,17(1):61-68. 